\section{QUESTÕES DE TRADUÇÃO EM \\ Jorge Luis Borges e ITAlo CALVINO}

\section{Maria Elisa Rodrigues Moreira}

Aprender a falar é aprender a traduzir [...].

Octavio Paz

A tradução tem sido tema de reflexão por parte de inúmeros estudiosos, que discutem suas possibilidades e limites, suas consequências e desdobramentos nos campos literário e poético. Mas não é somente aos pesquisadores e teóricos que a questão afeta, sendo que diversos escritores, para os quais a tradução é parte integrante de seu processo de trabalho - seja por atuarem também como tradutores, seja por terem traduzidas muitas de suas próprias obras para outros idiomas e suportes - também refletiram e escreveram sobre ela.

Octavio Paz, ao pensar a tradução, a aponta como uma função especializada da literatura, uma vez que considera qualquer tradução como uma operação literária, uma vez que implica necessariamente transformação do original, ainda que o original reverbere sistematicamente no texto traduzido:

O texto original jamais reaparece (seria impossível) na outra língua; entretanto, está sempre presente, porque a tradução, sem dizê-lo, o menciona constantemente ou o converte em um objeto verbal que, mesmo distinto, o reproduz [...].

Corroborando a posição de Paz acerca da imbricação entre o processo tradutório e o literário procuraremos, ao longo desse texto, identificar as posições de Jorge Luis Borges e Italo Calvino sobre a temática da tradução poética, assim como tecer considerações sobre possíveis desdobramentos e contribuições dessas reflexões para as teorias da tradução, e para a crítica literária de maneira geral.

A questão da tradução aparece em vários momentos da obra de Jorge Luis Borges, tanto em seus ensaios, resenhas, prólogos e entrevistas quanto em seus contos, embora de maneira assistemática. Com Italo Calvino observamos movimento semelhante, ainda que a reflexão sobre a tradução em sua obra seja menos frequente e suas concepçôes, por vezes, sejam bastante diversas das de Borges. Para ambos, no entanto, não interessa a construção de uma teoria da tradução, e sim a reflexão acerca de questões concretas e pon-
(PAZ, Octavio. Tradução, literatura e literalidade. Tradução de Doralice Alvez de Queiroz. Belo Horizonte: FALE/UFMG, 2006: 6.) 
(BORGES, Jorge Luis. Ensaio autobiográfico: 1899-1970. Tradução de Maria Carolina de Araújo e Jorge Schwartz. São Paulo: Companhia das Letras, 2009: 20.)

- (D'ANGELO, Biaggio. "El jardín de las versiones que se bifurcan. Una nota sobre la traducción en la obra de Borges". In: D'ANGELO, Biaggio. Borges en el centro del infinito. Lima: Fondo Editorial de la UNMSM/Universidad Católica Sedes Sapientiae, 2005: 37.) tuais relativas à tradução, seus problemas e possibilidades, a partir das quais aspectos mais amplos referentes à literatura emergem e são discutidos. A tradução aparece sempre como uma questão relativa ao fazer literário, e não apenas como um processo técnico de transposição idiomática.

A relação com a palavra foi marcante na vida de Borges, cuja família tinha profundos vínculos com a literatura, de modo que o escritor afirma ter sempre chegado "às coisas depois de encontrálas nos livros". Escritor prolífico, Borges realizou também inúmeras traduções, e reflexóes sobre linguagem e literatura perpassam toda sua obra. A reflexão sobre a tradução aparece explicitamente em diversas ocasióes, tanto em textos de caráter predominantemente ensaístico quanto em contos, alcançando outros desdobramentos com os muitos textos críticos dedicados a investigar a tradução na obra do escritor.

Segundo D’Angelo, se pensarmos a tradução como tentativa de compreensão de uma língua diferente de nossa própria língua e, com isso, de um universo cultural também diverso, a tradução em Borges "se torna comentário metafórico por extensão, forma de di-

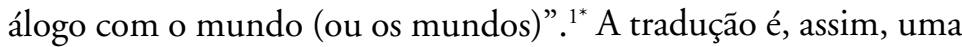
das formas pelas quais Borges realiza a mediação entre o mundo e os livros, apresentando-se em sua obra, se pensarmos no quanto a mesma é marcada pelo dizer de outra forma o que já foi dito por outro, de forma quase globalizante.

Para pensar uma obra que parece infinita, pautada em jogos de espelhos que a multiplicam e embaralham, torna-se necessário eleger aspectos que funcionem como um fio de Ariadne a nos guiar pelos inúmeros corredores desse projeto textual labiríntico. Procuraremos, assim, seguir três fios condutores na obra de Borges, três questôes pertinentes à temática da tradução: a tradução como modus operandi do processo de criação literária; a tradução e os papéis literários - autor/leitor/tradutor -; e a questão da validade e da importância da tradução para a literatura.

Observando a obra borgiana, não é difícil perceber o lugar proeminente ocupado pela tradução em seu processo criativo, uma vez que ela aparece com frequência seja como tema ficcional, como atividade prática ou como objeto de reflexão. Jogando constantemente com o caráter de farsa, de simulação da tradução - o usar uma palavra no lugar de outra palavra, criar um texto outro que seria uma

${ }^{1}$ Todas as traduções apresentadas são da autora. 
versão "exata" do primeiro -, Borges a converte em um de seus procedimentos ficcionais prediletos. Suas ficções são espelhos invertidos de outros textos, palavras recheadas de apócrifos, tradutores, manuscritos originais e citaçôes as mais diversas, uma tradução de sua biblioteca universal para a composição de uma escrita própria.

Encontram-se no meio de seus textos citaçôes integrais, traduçóes literais dos mais diversos autores, assim como nas traduções de seus livros alusōes ao fato de que tenham sido pensados originalmente no idioma para o qual foram traduzidos. É uma tradução que orienta, por exemplo, "O informe de Brodie", no qual é discutida justamente a questão da tradução: "Num exemplar do primeiro volume d'As mil e uma noites (Londres, 1840), de Lane, que meu querido amigo Paulino Keins conseguiu para mim, descobrimos o manuscrito que agora vou traduzir para o espanhol".* O início do conto já coloca em cena diversas das estratégias narrativas utilizadas por Borges na composição de sua ficção: a mistura entre real e ficção, a referência a outros textos, as ideias do manuscrito e da tradução. No caso específico, temos um manuscrito encontrado em uma tradução inglesa das Mil e uma noites, que será por sua vez traduzido ao espanhol.

Mas a questão da tradução não aparece apenas como referência ampla de estruturação do texto, voltando a ser apontada tematicamente ao longo da tradução do referido manuscrito que constitui a maior parte do conto:

O idioma é complexo. Não se assemelha a nenhum outro dos que eu tenha notícia. Não podemos falar de partes da oração, já que não há orações. Cada palavra monossílaba corresponde a uma ideia geral, que se define pelo contexto ou pelos gestos. A palavra $n r z$, por exemplo, sugere a dispersão ou as manchas; pode significar o céu estrelado, um leopardo, um bando de aves, a varíola, o salpicado, o ato de esparramar ou a fuga que se segue à derrota. $H r l$, ao contrário, indica o apertado ou o denso; pode significar a tribo, um tronco, uma pedra, um monte de pedras, o fato de empilhá-las, o congresso dos quatro feiticeiros, a união carnal e um bosque. Pronunciada de outra maneira ou com outros gestos, cada palavra pode ter um sentido contrário.

Nesse trecho Borges coloca em pauta a relação profunda entre língua e cultura, cujos ecos se desdobram no pensamento tradutório: as dificuldades de traduzir são inúmeras, e a tradução só "é possível porque se pode recriar a obra, tomar o texto como pretexto. Outra forma de tradução, creio que é impossível, sobretudo se pensarmos que dentro de um mesmo idioma a tradução é
" (BORGES, Jorge Luis. "O informe de Brodie". In: O informe de Brodie. Tradução de Davi Arrigucci Jr. São Paulo: Companhia das Letras, 2008: 85.)

(Ibidem: 91.) 
- (BORGES, Jorge Luis. "Problemas de la traducción (EI oficio de traducir)". Revista Sur, Buenos Aires, enerodiciembre 1976. Disponível em: www.ndet.org/foro/ showthread. php?tid=2881. Acesso em 21 fev. 2009.)

(Ibidem)

(BORGES, Jorge Luis. "O imortal". In: O Aleph. Tradução de Davi Arrigucci Jr. São Paulo: Companhia das Letras, 2008:7.)

'(GARGATAGLI, Ana; GUIX, Juan Gabriel López. "Ficciones y teorías en la traducción: Jorge Luis Borges". HISTAL, enero 2004. Disponível em: www.histal.umontreal.ca/espanol/documentos/ficciones_y_teorias_en_ la_traduccion.htm. Acesso em: 18 fev. 2009.) impossível". $2^{*}$ A multiplicidade de possibilidades de utilização da língua e seu vínculo com a cultura determinam a impossibilidade de uma tradução literal, uma vez que a criação textual é uma questão de escolhas, assim como o é a tradução. Isso implica o reconhecimento de que qualquer tradução será sempre a criação de outro texto, linguística e culturalmente diverso do primeiro:

Claro, traduzia pelo dicionário. Porém é o dicionário mesmo que induz ao erro. De acordo com os dicionários, os idiomas são repertórios de sinônimos, porém não o são. Os dicionários bilíngues, por outro lado, fazem crer que cada palavra de um idioma pode ser substituída por outra de outro idioma. O erro consiste em que não se leva em conta que cada idioma é um modo de sentir o universo e de perceber o universo.

Em "O Imortal” a tradução já havia aparecido como mote, de forma muito semelhante à utilizada por Borges em "O informe de Brodie": em 1929, em Londres, um antiquário de Esmirna oferece à princesa de Lucinge os seis volumes da Ilíada de Pope, sendo que no último deles ela encontra um manuscrito, "redigido em inglês e pródigo em latinismos", do qual o conto irá oferecer a versão literal. Mais uma vez percebemos a mistura de culturas e idiomas perpassando um relato de manuscritos e traduçōes, babel esta reafirmada logo no início do conto: "Manejava com fluidez e ignorância várias línguas; em pouquíssimos minutos passou do francês ao inglês e do inglês a uma conjunção enigmática de espanhol de Salonica com português de Macau."

Esses dois breves exemplos apontam situações específicas em que a tradução aparece como procedimento e tema ficcional nas obras de Borges, mas é importante destacar o que indicamos anteriormente, o quanto o caráter de simulação e reprodução da tradução são importantes em toda sua concepção literária:

as muitas palavras, disseminadas por toda sua obra, que descrevem os mecanismos desta tão denegrida operação do espírito: ler, interpretar, reproduzir, cotejar, copiar, ou suas consequências: versōes, fidelidade, literalidade.

Em "O Imortal" encontramos também os reflexos da segunda questão que indicamos, afeta à tradução e desdobrada por Borges em seus ensaios e contos: a questão dos papéis literários de au-

\footnotetext{
${ }^{2}$ Ainda que neste ensaio Borges refira-se especialmente à tradução da poesia, acreditamos ser possível extrapolar seu pensamento para pensar a tradução de maneira mais geral, uma vez que tal discussão reverbera em diversos outros pontos de sua obra.
} 
tor, leitor e tradutor, que remete à concepção borgiana da literatura. Em "Las dos maneras de traducir" o escritor argentino afirma acreditar na existência de duas classes de tradução: a primeira, correspondente às mentalidades românticas, pratica a literalidade; a segunda, correspondente às mentalidades clássicas, pratica a perífrase. Tais mentalidades, conforme Borges, equivalem a distintas concepções de literatura: uma, clássica, à qual sempre interessará a obra e não o artista, o texto e não seu autor; a outra, romântica, em que importa sempre mais o homem, o autor.

O tom irônico que utiliza para finalizar o trecho deixa antever qual dessas concepções literárias é mais cara a Borges, e a questão de uma maior valorização da obra do que do "homem" reverbera em muitos outros de seus textos. Em Borges, o contínuo jogo com a simulação, assim como seus desdobramentos, afetam também os papéis de autor, leitor e tradutor, que se intercambiam continuamente num processo que implica a perda de posiçôes rígidas e restritas para os mesmos, aspecto muitíssimo explorado em "Pierre Menard, autor do Quixote", "no qual a personagem Pierre Menard resolve reescrever o Quixote de Cervantes, palavra por palavra.

Segundo Pastormelo, " nesse conto Borges irá desenvolver ficcionalmente algumas das ideias que já perpassavam seus ensaios anteriores, atinentes à temática da tradução, criando com Menard uma representação irônica do que seria o "tradutor ideal": o Quixote de Menard pode ser lido, assim, como uma experiência limítrofe de tradução, que justamente por isso evidencia os limites de toda tradução. Os textos idênticos de Menard e Cervantes aparecem como alusão à imperfeição subjacente a toda tradução, ao absurdo de se ensejar uma tradução completamente literal, um texto absolutamente fiel ao original, tornando visível a necessária margem de infidelidade que deve marcar qualquer processo tradutório. Menard é, simultaneamente, leitor de Cervantes, tradutor do Quixote e autor de outro Quixote, por mais que este seja coincidente com o texto de Cervantes:

O texto de Cervantes e o de Menard são verbalmente idênticos, mas o segundo é quase infinitamente mais rico. (Mais ambíguo, dirão seus detratores; mas a ambiguidade é uma riqueza.) [...] Também é vivido o contraste dos estilos. O estilo arcaizante de Menard - estrangeiro, afinal - padece de alguma afetação. Não assim o do precursor, que maneja com desenfado o espanhol corrente de sua época.

Voltemos ao conto "O Imortal", no qual após a introdução recheada de alusões à tradução e à mistura de línguas diversas, à qual
"(BORGES, Jorge Luis. "Las dos maneras de traducir". La prensa, Buenos Aires, 01 ago. 1926. Disponível em: http://foro.elapeh.com/ viewtopic.php? $\mathrm{p}=191100$. Acesso em 17 fev. 2009.)

"(BORGES, Jorge Luis. "Pierre Menard, autor do Quixote". In: Ficções. Tradução de Davi Arrigucci Jr. São Paulo: Companhia das Letras, 2007: 34-45.)

* (PASTORMElO, Sergio. "Borges y la traducción". Borges Studies Online, Centre for Studies \& Documentation. 14 jan. 2001. Disponível em: http://www. borges.pitt.edu/bsol/pastorm1.php. Acesso em 17 fev. 2009.)

"(BORGES, Jorge Luis. "Pierre Menard, autor do Quixote". In: Ficções. op. cit.: 42-43.) 
(BORGES, Jorge Luis. "As versões homéricas". In: Discussão. Tradução de Josely Vianna Baptista. São Paulo: Companhia das Letras, 2008: 103-110.)

(BORGES, Jorge Luis. "O imortal". In: O Aleph. op. cit.: 18.$)$

(Ibidem: 20.) nos referimos anteriormente, Borges apresenta a "versão literal" do manuscrito encontrado. $\mathrm{O}$ manuscrito apresenta uma narrativa de Marco Flamínio Rufo, homem que tem notícias da existência da Cidade dos Imortais e de um rio que possibilita a imortalidade, partindo então em busca dos mesmos. Após diversos contratempos consegue encontrá-los; vivenciada, a dádiva já não parece maravilhosa, gerando uma posterior busca pelo retorno à condição de mortal.

Nesse percurso, marcado por labirintos multiplicáveis e palavras em diferentes idiomas que assomam à memória do narrador sem que ele saiba bem de onde, Rufo identifica entre os imortais Homero, o pai das histórias, figura emblemática em torno da qual proliferam as mais diversas discussões relativas à questão da autoria e da criação textuais. Homero, cujas obras traduzidas foram discutidas por Borges em "As versões homéricas"," obras que trazem a marca de uma autoria perdida e talvez anônima, um texto que persiste ao longo dos séculos em suas inúmeras versões, cotejadas pelo argentino; Homero, que, conforme nota incluída no conto pelo próprio Borges, era tido por Giambattista Vico como um "personagem simbólico".

O imortal Homero, que perguntado por Rufo sobre o que sabia a respeito da Odisseia, responde: "'Muito pouco', disse. 'Menos que o mais pobre dos rapsodos. Já terão passado mil e cem anos desde que a inventei.'”* Estamos diante do autor Homero, que desafirma com essa resposta sua própria autoria, sua autoridade sobre aquele texto que percorreu mais de um milênio e, ao mesmo tempo, lança parte da responsabilidade dessa autoria para aqueles rapsodos, leitores-narradores-tradutores de um texto que circula de boca em boca ao longo do tempo. Ao que Rufo acrescenta a seu relato:

Homero compôs a Odisseia; postulado um prazo infinito, com infinitas circunstâncias e mudanças, o impossível é não compor, nem uma única vez, a Odisseia. Ninguém é alguém, um único homem imortal é todos os homens. Como Cornélio Agrippa, sou deus, sou herói, sou filósofo, sou demônio e sou mundo, o que é uma cansativa maneira de dizer que não sou. ${ }^{*}$

É esse eco do passado que aparece nas palavras citadas por $\mathrm{Ru}$ fo ao longo de seu relato, em outros idiomas e rememoradas sem que o autor saiba de onde: são palavras de Homero. Temos assim um Rufo que é, ao mesmo tempo, Homero e muitos mais - o que equivale a dizer que ele não é ninguém: 
Quando o fim se aproxima, já não restam imagens da recordação; só restam palavras. Não é estranho que o tempo tenha confundido as que certa vez me representaram com as que foram símbolos do destino de quem me acompanhou por tantos séculos. Eu fui Homero; em breve, serei ninguém, como Ulisses; em breve serei todos: estarei morto."*

Encontramos ainda nos textos de Borges sobre Homero - retomando agora "As versões homéricas" - algumas reflexões do escritor argentino sobre a validade e a importância das traduções para a literatura, com elas abordando nossa terceira questão e encerrando essa breve leitura da tradução em Borges. Fica claro ao observarmos a obra de Borges que a tradução nunca ocupou lugar secundário na mesma, sendo pensada pelo autor como um dos muitos gêneros da literatura, tão importante quanto todos os demais:

Pressupor que toda recombinação de elementos é obrigatoriamente inferior a seu original é pressupor que o rascunho 9 é obrigatoriamente inferior ao rascunho $\mathrm{H}$ - já que não pode haver senão rascunhos. $\mathrm{O}$ conceito de texto definitivo não corresponde senão à religião ou ao cansaço. [...] Não há um bom texto que não pareça invariável e definitivo se o praticamos um número suficiente de vezes.

Essa valorização da tradução como possibilidade de maior conhecimento do texto abordado aparece de maneira enfática ainda em outros momentos, esclarecedores da concepção literária de Borges:

[...] a Odisseia, graças a meu oportuno desconhecimento do grego, é uma biblioteca internacional de obras em prosa e verso, desde os versos em rimas emparelhadas de Chapman até a Authorized Version de Andrew Lang ou o drama clássico francês de Bérard ou a saga vigorosa de Morris ou o irônico romance burguês de Samuel Butler.

A tradução, assim como todos os elementos que compõem o livro e acompanham o texto, aparece, para Borges, como parte daquele texto: a Odisseia é composta, para o escritor, por todas as suas traduções, pelas discussões acerca de Homero, pelas reflexões que suscita; o Quixote é também tudo isso, e acredito que ainda possamos incluir em seu rol de compósitos a versão do mesmo por Pierre Ménard. Cada nova versão faz apenas acrescentar possibilidades ao texto original, e original e traduções situam-se no mesmo patamar de importância, todos eles textos incompletos à espera de uma leitura que os atualize, ressignifique, recrie.

Além disso, Borges indica a importância das traduçôes não só para a circulação de textos fundamentais à biblioteca univer-
(Ibidem: 24.)

(BORGES, Jorge Luis. "As versões homéricas". In: Discussão. op. cit.: 103-104.)

* (lbidem.) 
sal, mas também por elucidarem aspectos da criação literária que não se deixam vislumbrar em outras situações - aspecto abordado também por Italo Calvino. É com essa discussão que ele inicia "As versōes homéricas":

Nenhum problema tão consubstancial com as letras e seu modesto mistério como o que propõe uma tradução. Um esquecimento animado pela vaidade, o temor de confessar processos mentais que adivinhamos perigosamente comuns, o esforço para manter intacta e central uma reserva incalculável de sombra velam as tais escrituras diretas. A tradução, por sua vez, parece destinada a ilustrar a discussão estética. $\mathrm{O}$ modelo proposto à sua imitação é um texto visível, não um labirinto inestimável de projetos pretéritos ou a acatada tentação momentânea de uma facilidade. *

Na tradução são perceptíveis e passíveis de análise os problemas técnicos da escritura, os processos de criação, a gênese do texto, enfim, a discussão estética que marca a literatura e que, muitas vezes, se encontra obscurecida na observação das estratégias poéticas de construção de narrativas. Dessa maneira, Borges reafirma a validade da tradução no campo literário: apesar de todas as dificuldades inerentes ao processo tradutório, o que conta são "as repercussões incalculáveis do verbal", "suas mil e uma possibilidades de irradiação.

Ao contrário de Borges, não são muitos os textos de Calvino que abordam diretamente a temática da tradução; entretanto, o assunto aparece em diversos pontos de sua obra, também estreitamente vinculado às concepções literárias que a norteiam. Sua atuação como tradutor e o longo período de trabalho na editora Einaudi, além do grande número de traduções feitas de suas próprias obras, tornam a tradução parte inseparável de sua profunda relação com a palavra e com o texto literário. Na obra de Italo Calvino, assim como em Borges, reflexão e ficção se imiscuem de tal modo que não é possível estabelecer limites rígidos entre os processos criativos e intelectuais que as direcionam, possibilitando sua leitura como um compósito de saberes que se articulam reticularmente.

Nesse espaço de múltiplas possibilidades articuladoras, traduzir é, para Calvino, uma forma de conhecer, de criticar, de interpretar o mundo, e nesse processo a literatura tem para o escritor um lugar especialmente reservado, uma vez que sua relação com o mundo foi, desde muito cedo, permeada pela palavra escrita, em especial pela palavra literária. É assim que o Sr. Palomar vai ecoar na ficção as reflexões do escritor: 
O senhor Palomar pensa que toda tradução requer uma outra tradução, e assim por diante. Pergunta-se a si mesmo: "Que quereria dizer morte, vida, continuidade, passagem para os antigos toltecas? E que poderá querer dizer para esses garotos? E para mim?”. Contudo, sabe que não poderia jamais sufocar em si a necessidade de traduzir, de passar de uma linguagem a outra, de uma figura concreta a palavras abstratas, de símbolos abstratos a experiências concretas, de tecer e tornar a tecer uma rede de analogias. Não interpretar é impossível, como é impossível abster-se de pensar.

Se temos em seus textos, por um lado, uma reflexão sobre a tradução calcada na concretude da prática editorial, como é o caso de "Sul tradurre", de 1963, vemos essa reflexão assumir um movimento contínuo, deixando suas marcas nos textos ficcionais e ensaísticos. Calvino tece sua rede textual, como indica o Sr. Palomar, utilizando-se dos mais variados elementos e artifícios. Pensar sobre a tradução é pensar sobre a linguagem, sobre as formas de comunicação entre os seres humanos, sobre as relações entre língua e cultura, sobre o que há de coesão e o que há de liberdade no uso de uma língua, sobre a literatura e suas possibilidades.

Percorrer essa rede narrativa de Calvino exige - assim como percorrer os labirintos borgianos - que se destaquem caminhos e escolham percursos que, se certamente são apenas alguns dentre os inúmeros possíveis, permitem-nos transitar pela obra sem que fiquemos à deriva, perdidos em sua imensidão. Traçaremos, portanto, outros três trajetos temáticos relativos à tradução que nos parecem essenciais no pensamento de Calvino sobre a mesma, e que dizem respeito diretamente às relações entre língua e cultura, às proximidades entre tradução e crítica e à qualidade da escrita.

A relação entre língua e cultura é patente em Calvino, e transparece em suas reiterações acerca da intraduzibilidade da literatura:

Quem lê literatura traduzida já sabe que está fazendo alguma coisa aproximativa. A escritura literária consiste cada vez mais num aprofundamento no espírito mais específico da língua (em suas pontas extremas de uma máxima expressividade ou neurose linguística e de um máximo de anonimidade, de neutralidade 'objetal'), o que a torna cada vez mais intraduzível.

Em outro texto, afirma:

Traduzir é uma arte: a passagem de um texto literário, qualquer que seja o seu valor, para uma outra língua requer sempre algum tipo de milagre. Sabemos todos que a poesia em versos é intraduzível por definição; mas a verdadeira literatura, também aquela em prosa,
*(CALVINO, Italo. Palomar. Tradução de Ivo Barroso. São Paulo: Companhia das Letras, 1994: 90.) "(CALVINO, Italo. "Italiano,
uma língua entre as outras
línguas". In: Assunto encer-
rado: discursos sobre litera-
tura e sociedade. Tradução
de Roberta Barni. São Pau-
lo: Companhia das Letras,
2009: 142.$)$ 
(CALVINO, Italo. "Tradurre è il vero modo di leggere un testo". In: Barengui, Mario (org.). Italo Calvino. Saggi. 1945-1985. Milano: Mondadori, 2001, v. 2: 1826-1827.)

- (CALVINO, Italo. "Italiano, uma língua entre as outras línguas". op. cit.: 144)

- (CALVINO, Italo. Sul tradurre. In: Barengui, Mario (org.). Italo Calvino. Saggi. op. cit.: 1778.) trabalha propriamente sobre a margem intraduzível de qualquer língua. $\mathrm{O}$ tradutor literário é aquele que coloca a si mesmo inteiro em jogo para traduzir o intraduzível.

O texto literário não pode, assim, nunca ser traduzido por completo, nunca será construída uma tradução idêntica ao original, uma vez que ambos os textos, original e traduzido, assentamse em diferentes solos culturais, tanto em sua produção quanto em sua recepção. A tradução será sempre uma aproximação, um texto outro que dialoga com aquele original e com os dois idiomas em questão. E é na forma como se estabelece esse diálogo que se encontraria a principal origem da diferença entre as traduçôes bemsucedidas e as traduções inadequadas.

Se cada idioma apresenta, como afirma Calvino, possibilidades e limites exclusivamente seus - “[...] cada língua tem limites, mas também possibilidades que são exclusivamente suas"* -, no jogo de traduzir o intraduzível o tradutor precisará mais do que do conhecimento das línguas com as quais trabalha. Ele precisa contactar o espírito de cada uma delas e descobrir como transmitir sua "essência secreta". Ou seja, o tradutor precisa conhecer a língua e a cultura que a formou para que o texto traduzido apresente-se não só como uma versão dicionarizada de seu original, mas seja capaz de reproduzir de forma adequada o que aquela obra tem de único, seus efeitos e peculiaridades narrativas, mantendo suas características mais tênues e sutis.

A tradução é, assim, vista por Calvino como um diálogo entre dois idiomas que devem ser explorados pelo tradutor para deles extrair, com a máxima liberdade e criatividade possível, o que pode haver de mais particular em cada texto e contexto de produção, garantindo sua aproximação com o original e, ao mesmo tempo, a sensação de que a obra foi produzida diretamente no idioma para o qual foi traduzida, "uma prosa que se leia como se tivesse sido pensada e escrita diretamente em italiano". É interessante observarmos, em relação a esse aspecto, como o próprio escritor por vezes se embaraça nas traduçôes de seus textos em virtude dessa variação cultural entre idiomas distintos. Em sua introdução ao livro Italo Calvino: uno scrittore pomeridiano, William Weaver, que foi durante muitos anos o tradutor das obras de Calvino para o inglês, narra alguns episódios relativos ao processo de tradução do livro Palomar. Weaver afirma que Calvino, em seus últimos livros, passou a acompanhar de perto e intervir nas traduções para o inglês, 
inserindo modificações "no seu inglês", que era muito mais teórico que idiomático. Dentre essas intervençôes Weaver destaca o uso da palavra feedback, pela qual Calvino teria ficado fascinado e que insistia em inserir no texto, ainda que o tradutor percebesse a inadequação da mesma para um texto literário na língua inglesa:

$\mathrm{Na}$ tradução de Palomar permaneceu fascinado pela palavra feedback. Continuava a inseri-la no texto, e eu, com muito tato, continuava a eliminá-la. Não conseguia fazê-lo entender que, assim como $c h a-$ risma, input e bottom line, também feedback, por mais que pudesse soar bem a um ouvido italiano, não era um termo apropriado para uma obra literária em inglês."

É, portanto, nessa fronteira cambiante que se situa a tradução, é o fato de ser simultaneamente o mesmo texto e outro texto completamente diverso que garante sua importância e que possibilita resultados narrativos interessantes e por vezes surpreendentes. É isso que permite que um autor como Calvino afirme que, por vezes, não se reconhece em sua própria obra traduzida, o que não implica que essas traduçôes não tenham tido resultados satisfatórios. É isso que garante que a tradução seja um jogo sem vencedores, um jogo com o intraduzível, no qual o melhor resultado possível será sempre apenas uma aproximação.

Ao mesmo tempo em que aponta a intraduzibilidade de qualquer texto literário, Calvino lança a discussão sobre a tradução num outro campo, não mais restrito à concretude do processo tradutório. Ao afirmar que traduzir é o verdadeiro modo de se ler um texto, o escritor faz um movimento mais amplo, de aproximação entre tradução, leitura e crítica. Segundo Calvino, o processo de traduzir um texto exige que se debruce sobre o mesmo, por vezes trabalhando palavra a palavra na tentativa de descobrir as melhores alternativas, de encontrar os melhores caminhos diante de grandes dificuldades. Esse processo exige uma leitura profunda do texto, uma leitura que o ressignifique para outro contexto, que o interprete e possibilite sua recriação numa outra linguagem.

E Calvino amplia ainda mais o campo do movimento tradutório, abrangendo nesse processo não só o ato de traduzir, mas também a leitura de traduções como instrumental e método crítico e analítico. Se num primeiro momento ele afirma que um autor só é verdadeiramente lido quando traduzido, ele amplifica a questão ao indicar que a leitura verdadeira ocorre também no momento em que se confronta o texto original e sua tradução, ou ainda de forma mais abrangente, várias traduções de um mesmo original:
* (WEAVER, William; PETTIGREW, Damien (orgs.). Italo Calvino: uno scrittore pomeridiano. Intervista sulla'arte della narrativa. Roma: Minimum Fax, 2003: 28-29.) 
- (CALVINO, Italo. Sul tradurre. In: Barengui, Mario (org.). op. cit: 1779.)
-(CALVINO, Italo. Se um viajante numa noite de inverno. Tradução de Nilson Moulin. São Paulo: Companhia das Letras, 1999: 74.)

- (CALVINO, Italo. Seis propostas para o próximo milênio. 2. ed. Tradução de Ivo Barroso. São Paulo: Companhia das Letras, 1995.)
É um exercício, sobretudo, que gostaríamos de recomendar não apenas aos críticos mas a todos os bons leitores: como é notório, se lê verdadeiramente um autor apenas quando se o traduz, ou se confronta o texto com uma tradução, ou se comparam versôes em línguas diversas.*

Nesse sentido, com Calvino assim como com Borges, é possível pensarmos a tradução como um processo que permite desnudar a criação literária, um processo no qual se coloca em questão, de forma controlada e precisa, o fazer literário. Com isso, a tradução pode funcionar como método também para a crítica, que a partir dela pode vislumbrar as dificuldades, os sucessos, as boas soluções encontradas pelos escritores para desenvolver seus trabalhos.

É o que se percebe quando, em Se um viajante numa noite de inverno - romance que poderia ser tratado como um texto de teoria da literatura, protagonizado pelo Leitor e pela Leitora, e no qual são ficcionalmente discutidos os mais diversos aspectos concernentes à literatura, como as ideias de autor, leitor, bibliotecas, editoras, originais, cópias, falsificações, e inclusive a tradução -, o professor Uzzi-Tuzii inicia a tradução oral de um texto numa língua quase desconhecida:

Ademais, o professor Uzzi-Tuzii começara sua tradução oral como se não estivesse bem seguro do encadeamento das palavras umas com as outras, voltando ao início do período para reordenar os deslizes sintáticos, manipulando as frases até moldarem-se completamente, amarrotando-as, retalhando-as, detendo-se em cada vocábulo para ilustrar-lhe os usos idiomáticos e as conotaçōes, acompanhando-se de gestos envolventes como se para convidar você a satisfazer-se com equivalências aproximativas, interrompendo-se para enunciar regras gramaticais, derivaçōes etimológicas, citaçōes de clássicos. Mas, quando você já está convencido de que para o professor a filologia e a erudição significam mais que a narrativa, percebe que se trata do contrário: aquele invólucro acadêmico só serve para proteger o que o relato diz e não diz, o sopro interior sempre a ponto de perder-se em contato com o ar, o eco de um saber desaparecido que se revela na penumbra e nas alusões silenciadas.

Calvino explicita nesse trecho de seu romance a tradução como o que ele chamou de um trabalho de dúvidas, conceito que pode ser aplicado também ao processo de criação literária, à escrita, ao que ele identifica em seu processo criativo como "tradução em palavras" de uma imaginação visiva, de um mundo concreto." Traduzir e dedicar-se à leitura da tradução transformam-se, assim, nas reflexôes de Calvino, em instrumentos de leitura, em possibi- 
lidade de elaboração crítica e também em uma forma de investigar a literatura em seus mais variados aspectos.

Nesse ponto, o escritor italiano - de maneira semelhante ao que indicamos em relação a Jorge Luis Borges - se aproxima da questão abordada por Octavio Paz ao discutir a tradução poética e sua simetria inversamente proporcional à criação poética, na qual precisa algumas diferenciações entre os trabalhos de leitura, crítica e tradução:

O ponto de partida do tradutor não é a linguagem em movimento, matéria-prima do poeta, mas a linguagem fixa do poema. Sua operação é inversa à do poeta: não se trata de construir com signos móveis um texto móvel, mas de desmontar os elementos deste texto, pôr de novo em circulação os signos e devolvê-los à linguagem. Até aqui, a atividade do tradutor é parecida com a do leitor e a do crítico: cada leitura é uma tradução, e cada crítica é, ou começa a ser, uma interpretação. Entretanto, a leitura é uma tradução dentro do mesmo idioma, e a crítica é uma versão livre do poema ou, mais exatamente, uma transposição. Para o crítico, o poema é um ponto de partida para outro texto, o seu, enquanto que o tradutor, em outra linguagem e com signos diferentes, deve compor um poema análogo ao original. Assim, em um segundo momento, a atividade do tradutor é paralela à do poeta, com esta diferença marcante: ao escrever, o poeta não sabe como será seu poema; ao traduzir, o tradutor sabe que seu poema deverá reproduzir o poema que tem diante dos olhos. Em seus dois momentos a tradução é uma operação paralela, ainda que em sentido inverso, à criação poética. O poema traduzido deverá reproduzir o poema original, que, como já foi dito, não é sua cópia e sim sua transmutação."

Apesar de extensa, a transcrição do trecho acima é elucidadora para nossa discussão, uma vez que sistematiza questōes discutidas esparsamente por Calvino e aqui apontadas por nós. A tradução confirma-se como procedimento literário, que ultrapassa em muito uma simples transposição idiomática de textos, e que se desdobra nos estudos literários de muitas e diversas maneiras.

Para finalizarmos nosso percurso pelo pensar a tradução em Italo Calvino, chegamos a uma questão um tanto polêmica, que é o "escrever bem”. Calvino afirma que escrever bem é condição essencial para que se seja um tradutor, e que mais importante que os dicionários é a consecução da harmonia e lógica interna do conjunto textual. Se a tradução exige o conhecimento da língua e da cultura que a produziu, e se traduzir é também recriar um texto com possibilidades que só aquele idioma lhe permite, é fundamental para que se tenha uma boa tradução que se tenha, também, um bom escritor. 
Apesar de algumas diferenças entre as abordagens dos dois autores, interessa-nos destacar a presença da reflexão sobre a tradução poética em suas obras, e os desdobramentos dessas reflexões no processo criativo dos próprios autores, marcados por um projeto literário que apresenta muitos pontos de convergência. Ainda que não tracem uma teoria da tradução, Borges e Calvino apresentam em seus estudos específicos sobre a tradução, em seus textos ficcionais que têm a mesma por tema, na estruturação de sua obra e em suas concepções acerca da literatura elementos que em muito contribuem para que pensemos o lugar ocupado pela tradução no campo literário, e nas consequências e possibilidades abertas pelos processos tradutórios para a produção, a teoria e a crítica literárias e culturais. Valorizando a tradução, eles não deixam de perceber e apontar suas dificuldades, mas lembram-nos todo o tempo que essas dificuldades são também a matéria-prima para inúmeras e variadas possibilidades narrativas.

\section{Maria Elisa Rodrigues Moreira}

Doutoranda em Literatura Comparada e mestre em Teoria da Literatura pela UFMG - Universidade Federal de Minas Gerais. Bolsista do CNPq, desenvolve pesquisas sobre as obras de Jorge Luis Borges e Italo Calvino, tendo publicado o livro Saber narrativo: proposta para uma leitura de Italo Calvino (Tradição Planalto, 2007) e diversos artigos, como "Jorge Luis Borges e Italo Calvino: disseminações e diluições de textos outros" e "Reflexões sobre autoria em Jorge Luis Borges e Italo Calvino”.

\section{Resumo}

Palavras-chave: tradução; literatura; crítica; Italo Calvino; Jorge Luis Borges.

O presente ensaio procura apontar as reflexões sobre a tradução presentes na obras de Jorge Luis Borges e Italo Calvino, identificando como para estes autores a tradução, assim como suas possibilidades e limites, é pensada em íntima relação com outras concepçôes de literatura que permeiam suas obras. Ainda que seus escritos sobre o tema sejam assistemáticos e não se possa falar de uma "teoria da tradução" relativamente à obra desses autores, suas reflexões sobre os processos tradutórios e os desdobramentos das mesmas em suas obras ficcionais certamente produzem ecos na crítica e na teoria literárias. 
Abstract

The present text aims to present reflections on the translations which are included in Jorge Luis Borges and Italo Calvino's works. It identifies how these writers saw translations, as well as their possibilities and limits, in close relationship with other literary concepts which permeate their works. Even when their works about the theme are not systematical and it is not possible to talk about a "translation theory" in relation to these authors' works, their reflections on the translation process and the developments of the same in their fictional works, certainly produce echoes in criticism and literary theories.

\section{Resumen}

El presente ensayo busca señalar las reflexiones sobre la traducción presentes en las obras de Jorge Luis Borges e Italo Calvino, identificando cómo para esos autores la traducción, así como sus posibilidades y límites, está pensada en íntima relación con otras concepciones de literatura presentes en sus obras. Aunque sus escritos sobre el tema sean asistemáticos y no se pueda hablar de una "teoría de la traducción” relativamente a la obra de esos autores, sus reflexiones sobre los procesos traductorios y los despliegues de las mismas en sus obras ficcionales ciertamente producen ecos en la crítica y en la teoría literarias.
Key words: translation; literature; criticism; Italo Calvino; Jorge Luis Borges.

Palabras clave: traducción; literatura; crítica; Italo Calvino; Jorge Luis Borges.
Recebido em 11/06/2009

Aprovado em 25/07/2009 